\title{
UTILIZATION OF YOUTH FRIENDLY SERVICES AND ASSOCIATED FACTORS IN MEKELLE TOWN, TIGRAY, NORTHERN ETHIOPIA
}

\author{
Kalayu Kahsay ${ }^{1}$, Semarya Berhe ${ }^{2^{*}}$, Mussie Alemayehu ${ }^{3}$ \\ ${ }^{1}$ Sheba University, Department of Nursing, Mekelle, Ethiopia \\ ${ }^{2}$ Department of Nursing and Midwifery, College of Health Sciences, School of Allied Health Sciences, Addis \\ Ababa University, Ethiopia \\ ${ }^{3}$ Department of Public Health, College of Health Sciences, Mekelle University, Ethiopia
}

\begin{abstract}
Background: Ethiopia is the second populated country in sub-Saharan Africa with 82 million people; more than half of them are under the age of 25 . Youth throughout the world are susceptible to health risks because they lack adequate knowledge, adventure, and lack of guidance about sexual and reproductive health and related concerns. Limited in being a youth-friendly, affordable, or confidential. Moreover, the environment within which sexual and reproductive health services are provided is often not sensitive to the special needs of this youth population. Little is known about the level of utilization to the standard and the predators that influence the utilization.
\end{abstract}

Objective: To assess utilization of youth friendly services and associated factors in Mekelle city.

Methods: A community based cross-sectional study, which contains both quantitative and qualitative methods, were conducted from December-7-18, 2012. Two stage cluster sampling techniques were used to select study participants. Descriptive analysis was used to show the characteristics of the youths and levels of youth friendly services utilization. To depict the effect sizes of the predators for the youth friendly utilization, multivariable logistic regression was used.

Result: A total of 330 subjects were included in the study with response rate of $100 \%$. Of these, nearly three-fourth (69.1\%) of the respondents used youth friendly services where as $47.1 \%$ reported that they did not know where to go as a main reason for not using youth friendly services. Majority of the respondents 295 (89.4\%) had information about youth friendly services and $35.5 \%$ of them heard the information from media. However, $166(53.3 \%)$ of the respondents had negative attitude towards youth friendly service utilization. Source of information about youth friendly services, knowledge and with whom you start sex have found to be independent predictors of utilization of youth friendly services.

Conclusions and Recommendations: Though attitude towards youth friendly service was negative, utilization was good. So, the government should intervene on the attitude of the participants to improve the utilization of the service.

Key words: Youth, friendly, service, associated factors, utilization

\section{INTRODUCTION}

Youth friendly services should offer a wide range of sexual and reproductive health services relevant to adolescents' needs.

These services include sexual and reproductive health counseling, contraceptive counseling and provision (including emergency contraception) sexually transmitted infection/HIV prevention,

*Corresponding author:

Email: semitaye@yahoo.com counseling and testing, treatment and care, prenatal and post-partum care, sexual abuse counseling, relationship counseling, and safe abortion and abortion-related services [1].

World Health Organization (WHO) has estimated that $70 \%$ of the premature deaths among adults are largely due to behaviors initiated during adolescence [2]. In addition to this, UNICEF and USAID have indicated that $17 \%$ of young women and $14 \%$ of young men aged $20-24$ years were sexually active by 
the age of 15 years [3]. At least 80 percent of subSaharan Africa's youths are sexually experienced and the statistics on having had intercourse by the age of 20 are: 73 percent of Liberian women aged 15 to 19; 15 percent of Nigerian women; 49 percent of Ugandan women; and 32 percent of Botswana women [4].

Barriers to access health care for young people continue today. These barriers include inconvenient locations, limited hours of operation, unsupportive provider attitudes, and a lack in the quality of services, a lack of confidentiality, a lack of privacy and high costs of the services [3]. Moreover, most of youth, parents and health care provider are not well aware of the sexual and reproductive health rights and needs of youth. In addition, most of youths are not aware of the type of sexual and reproductive health services available in the existing service outlets. But they did not have adequate information about when these services could be accessed, who provides the services, and how they would be served. This is a major obstacle in getting appropriate sexual\& reproductive health services for adolescents $\&$ youth [5].

Ethiopia is the second largest country in sub-Saharan Africa with a growing population that is currently at 82 million people-where approximately $40.0 \%$ of the population falls between the ages of 10-29 [6]. Moreover, the Tigray region, $20 \%$ population accounts for the ages of 15-24. Mekelle zone has an estimated total population of 256,000 of whom 84,480 (33\%) are youth [7]. However, a considerable proportion of the youth practice unsafe sex and sex at an early age and the utilization of $\mathrm{RH}$ services in the existing health care system by young people is very low. As a result, there is a high rate of unwanted pregnancies which often result in abortions and their complications. The majority $(67.2 \%)$ of those seeking treatment for an incomplete abortion are under 24 years of age [3]. Another major health threat that affects young people is STIs including HIV. It is estimated that one quarter (26\%) of the HIV-positive people in Ethiopia are between the ages of 10 and 24 [8].

Even though youths are at risk of different reproductive health problems, there are no studies that documented levels of utilization and factors associated with youth friendly service utilization in Tigray region. This study tried to point out magnitude and factors associated with Youth Friendly Services (YFS) utilization among youths in
Mekelle town, Tigray region, North Ethiopia. The findings of this study can be used as a baseline data for policy makers and significant others to improve YFS.

\section{METHODS}

Study area and setting

A community based cross-sectional study involving both quantitative and qualitative (focus group discussion and in-depth interview) was conducted from December 7-18, 2012. The study was conducted in Mekelle town, Tigray region, Northern part of Ethiopia. The area has a total population of 256,000 , of whom 84,480 (with 41,395 males and 43,085 females) are youth. Tigraway is the dominant ethnic group in Mekelle. The city is divided into seven local administrations (sub cities) and one hundred sub-districts (ketena). The health services system is improving, which consists of both public and private health care providers. There are eight health centers, 38 private clinics four governmental and 3 private hospitals [9]. All the youths found in the selected ketena were included in the study

\section{SAMPLING}

The sample size was determined using single population proportion formula with the assumption of $95 \%$ confidence level, the margin of error of $5 \%$ and expected prevalence of youth service utilization $88 \%$ based on a study conducted in Harar, East Ethiopia [10]. The final sample size was 330 including $10 \%$ non-response rate. Inclusion criteria for the study was age between15-24 and being resident (youth) in the district for at least six months. But all youth who are mentally incompetent and sick/ill at the time of study were excluded from the study. The study participants were selected using two stage cluster sampling technique. The 7 sub cities are Kedamay Weyane (14 ketena), Hawelti (16 ketena), Ayder (16 ketena), Semen (17 ketena), Hadnet (9 ketena), AdiHaki (13 ketena) and Quiha (15 ketena). From the entire city, 75,294 households were counted, which results in, on average, family size of 3.4 [9]. The sub cities are considered as homogeneous with respect to the youth service utilization; thus, four sub cities were selected using simple random sampling technique. In the selected local administrative, there were 52 sublocal administrations (ketena) and only 16 were selected out of those with the presumption of homogeneity of service utilization. The 16 ketena contained 11,193 households. The number of respondents in each selected ketena was assigned 
using the proportional probability sampling based on the sampling frame existed in the local administration. Finally a systematic sampling technique was employed to approach the study participants. When there appears more than two eligible youths in the selected households, only one was used to be considered as random to avoid the cluster effect on the characteristics of the youths within a household.

The selection of participants of focus group discussion and in depth interview was performed using purposive sampling technique with a consideration of sex of convenient individuals during FGD and work place respectively. The FGD and indepth interview consist of similar ideas with a questionnaire.

\section{Method of data collection}

Quantitative

The principal investigator provided a two days training for 6 clinical nurses as data collectors and two BSc nurses as supervisors. Interview of the youths was conducted in a convenient place to express freely their feelings and ideas. The data was collected using structured interviewer administered questionnaires. The questionnaire was adapted from different studies considering the local situations [1013]. Questionnaires were prepared first in English then translated into the local language (Tigrigna) by language experts. To check whether the translation was consistent with the English version the questionnaire was back translated to English by an independent language expert. Before the actual data

Table1: Socio- Demographic and economic characteristics of youths, Mekelle town, 2013 . $(n=330)$

\begin{tabular}{lll}
\hline Characteristics & Number & Percent \\
\hline Sex & & \\
\hline Male & 172 & 52.1 \\
Female & 158 & 47.9 \\
\hline Age (years) & & \\
\hline 15-19 & 126 & 38.2 \\
20-24 & 204 & 61.8 \\
\hline Religion & & 73.6 \\
\hline Orthodox & 243 & 20 \\
Muslim & 66 & 6.4 \\
\hline Others* & 21 & \\
\hline
\end{tabular}

Ethnicity

\begin{tabular}{lcc}
\hline Tigre & 321 & 97.3 \\
Amhara & 7 & 2.1 \\
Afar & 2 & 0.6 \\
\hline
\end{tabular}

Marital status

Married

Has a boy / girl friend

Have no any partner
21.2

49.1 
collection, the questionnaire was pre-tested on $5 \%$ (17 youths) in Wukro town which is $45 \mathrm{~km}$ North of Mekelle. Moreover, in occasions where the sampled youths were not accessed during the first visit, another two revisits were used to lessen the nonresponse rate.

Focus group discussion and in-depth interview guidelines were used to explore ideas of the youth and health care providers about YFS utilization. For the findings from these were triangulated with the quantitative findings. During the FGDs and in-depth interview participants were informed about their purpose and process of the FGD and in-depth interview to obtain informed consent of each participant. Two persons were assigned for note taking and tape recording while the principal investigator facilitated the discussion in the FGD. Moreover, the investigators had conducted the in-

Table 2: Knowledge of the study participants about youth friendly service Mekelle town, 2013 ( $n=330)$

Characteristics $\quad$ Frequency Percent

Ever heard information about family planning

\begin{tabular}{lrr}
\hline Yes & 312 & 94.5 \\
No & 18 & 5.5 \\
\hline Source of information & 117 & 35.5 \\
\hline Media & 80 & 24.2 \\
School teacher & 98 & 29.7 \\
Health institution & 35 & 10.6 \\
Friends & 35 \\
\hline
\end{tabular}

Know methods/ contraceptives in preventing pregnancy

\begin{tabular}{lrr}
\hline Yes & 320 & 97 \\
No & 10 & 10 \\
\hline
\end{tabular}

Knew where they get contraceptive methods

\begin{tabular}{lll}
\hline Yes & 319 & 96.7 \\
No & 11 & 3.3 \\
\hline
\end{tabular}

Ever heard of SRH (Sexual and Reproductive Health)

\begin{tabular}{lrr}
\hline Yes & 284 & 86.1 \\
No & 46 & 13.9 \\
\hline
\end{tabular}

Ever heard of voluntary counseling and testing (VCT) 
depth interview. Two FGD was conducted separately for males and females. Each FGD consisted of eight participants. Each FGD took an average of 1 FGD in 1 and a half hour. Some of the issues arose on FGDs and in-depth interview were: the attitudes towards practicing YFS, reasons for not practicing YFS, who were the influential group in utilization of the YFS and its reasons and what was the main problem encountered in youths (in-depth interview). Finally, the recorded discussions and notes were transcribed into English manually.

\section{MEASUREMENT}

To measure youth's knowledge of youth friendly service utilization ten questions were used to construct composite score: High knowledgeable those who knew $80 \%$ and above distinct characteristics of YFS from knowledge questions. Low knowledgeable - those who knew less than $80 \%$ of the distinct characteristics of YFS from the knowledge questions. To measure youth's attitude on YFS, another ten questions were used to construct composite score: "Positive Attitude"those who scored above a mean on attitude measuring YFS questions and "Negative Attitude" those who scored a mean or below he mean in the attitude measuring YFS questions. The service utilization was defined as those who used and those who didn't use the YFS.

\section{DATA ANALYSIS}

The quantitative data were entered, cleaned and analyzed using SPSS 20.0 for windows (SPSS Illinois, Chicago). Descriptive analysis was carried out for each of the variables. Bivariate analyses were done to scrutinize the potential candidates for the multivariable logistic regression finally; variables which showed significant association with the dependent variable in the bivariate analysis were entered into a multivariate logistic regression model to identify their independent effect sizes. Moreover, the collinearity among the independent variables was checked among the potential variables for collinearity using tolerance test. Data from the focus group discussion and in-depth interview were translated and transcribed into English and categorized accordingly to main thematic areas manually. The findings were presented in narrations and triangulated with the quantitative results verbatim

\section{ETHICAL CONSIDERATIONS}

Ethical clearance was obtained from Mekelle University; College of Health Sciences Ethical review board. The ethical clearance describes that there was no any intervention made on the study youths.
Informed consent explained the non-malfeasance and the beneficence of the findings from the study for the betterment of the youth friendly services was obtained from each participant prior to interview. The participants were informed on their right to participate or deny the participation at any stage of the interview.

\section{RESULTS}

\section{Socio-demographic characteristics}

All of the supposed study participants were participated in the study. Two hundred and four $(62 \%)$ of the participants were in the age range of 20-24, with mean age of $20.23(S D \pm 2.5)$ Years. More than a half of the youths were males $172(52 \%)$, Tigray in ethnicity $321(97.2 \%)$ and followers of orthodox Christianity 243 (73.6\%) were dominants. Out of the total of participants, $168(50.9 \%)$ and 144 (44\%) were students in occupation and attended secondary school, respectively. Of the total youths, $182(55.2 \%)$ reported that they didn't have their own monthly income [Table 1].

Knowledge of Youths towards Youth Friendly Service

Three hundred and twelve (94.5\%) and 320 (97\%) of the participants heard of the family planning and knew methods for preventing pregnancy respectively. About 284 (86.1\%) of the youths reported that they heard of sexual and reproductive health (SRH) information. Out of the total respondents, 310 (94\%) of the respondents had information about voluntary counseling and testing (VCT) and 248 (75\%) of them knew where they could access recreation and library service respectively.

These findings were also supported by the result of the FGD and in-depth interview. Regarding to VCT all respondents agreed that it is important; they also mentioned that nowadays many people in their locality underwent VCT to know their self-status.

In depth interview from Mekelle health center (25, Female, Nurse) expressed her view as follows

"......... many youths were undergoing VCT, but, the main problem here is to bring behavioral change because most of youths come immediately to be tested after they engaged in risky behavior like unsafe sex........"

Almost all (99\%) of the youths reported that they had heard of sexually transmitted infections (STIs) and $318(96.4 \%)$ believed that those diseases are preventable.

All the FGD discussants knew about STIs and were able to mention some of their names and mode of 
transmission. Media and health professionals were the main sources of information.

A participant of FGD, (23 year's old, female, Orthodox) expressed her view as follows: contraceptives, including condom should be easily available in the health institutions. In this study, 195 (59.0\%) and 155 (47.0\%) youths agreed that VCT service should be available in the health institution

Table 3: Attitude of the study participants about youth friendly service Mekelle town, 2013 ( $n=330$ )

\begin{tabular}{|c|c|c|c|}
\hline Variables $(n=330)$ & Disagree & Not sure & Agree \\
\hline Do you think a boy/girl should have sex before marriage & $212(64.2 \%)$ & $43(13 \%)$ & $77(22.7 \%)$ \\
\hline Discussing about condom or contraceptive with people promotes promiscuity & $215(74.3 \%)$ & $39(11.8 \%)$ & $46(13.9 \%)$ \\
\hline Youth does not need sexual and reproductive health information. & $270(81.8 \%)$ & $18(5.5 \%)$ & $42(12.8 \%)$ \\
\hline $\begin{array}{l}\text { Providing youth sexual and reproductive health information and education leads } \\
\text { them to high-risk sexual behaviors. }\end{array}$ & $247(74.9 \%)$ & $41(12.4 \%)$ & $42(12.8 \%)$ \\
\hline $\begin{array}{l}\text { Educational materials about pregnancy, STDs and AIDS Prevention methods should be } \\
\text { available in the community and health institution. }\end{array}$ & $167(50.6 \%)$ & $36(10.9 \%)$ & $127(38.5)$ \\
\hline $\begin{array}{l}\text { The best method for prevention of unwanted pregnancy and STDs/AIDS is abstinence } \\
\text { until marriage. }\end{array}$ & $162(49.1 \%)$ & $56(17 \%)$ & $112(34.0 \%)$ \\
\hline HIV/AIDS is a curse sent from God rather than it is due to human misbehavior & $186(56.4 \%)$ & $76(23 \%)$ & $68(20.6 \%)$ \\
\hline Contraceptives, including condom should be easily available in the health institution. & $88(26.7 \%)$ & $35(10.6 \%)$ & $207(62.7 \%)$ \\
\hline VCT service should be available in the health institution. & $109(32.8 \%)$ & $26(7.9 \%)$ & $195(59.0 \%)$ \\
\hline The YFS provided currently in the health institution are adequate. & $118(35.7 \%)$ & $57(17.3 \%)$ & $155(47.0 \%)$ \\
\hline
\end{tabular}

".....Most of the youth had awareness on F/P, VCT, STI and HIV/AIDS. But I had doubts about their knowledge on SRH. This is a new for me and I need some explanation about this....."

Most (91.5\%) believed that HIV/AIDS were not curable and $99 \%$ of the youths knew how HIV is transmitted [Table 2]. The composite measure of knowledge showed that 295 (89.4\%) were in the category of good knowledge, $26(7.9 \%)$ in moderate knowledge and only $9(2.7 \%)$ in low knowledge.

\section{Attitude of Youths towards Youth Friendly Services} In this study, 77 (22.7\%) youths agreed that a boy/ girl should have sex before they are married. In addition 46(13.9\%) respondents assumed that discussing about condom or contraceptive with people promotes promiscuity respectively. Surprisingly, 42 (12.8\%) youths agreed that providing information and education for youths about sexual and reproductive health led them to high-risk sexual behaviors. More than one third 127 (38.5\%) of the youths agreed that educational materials about pregnancy, STDs and HIV/AIDS prevention methods should be available at community and health institution levels. The best method for prevention of unwanted pregnancy and HIV/AIDS /STDs was abstinence until marriage in which almost one third $(34.0 \%)$ of the youths agreed, because if there is no sexual intercourse, there is no risk of STDs. More than half, $62.7 \%$ of the youths agreed that and the YFS provided currently in the health institution are adequate [Table 3]. The composite measure of attitude indicated that 154 (46.7\%) of the youths had a positive attitude on YFS utilization. In this study, almost one fifth 68 (20.6\%) of the youths agreed that HIV/AIDS is a curse sent from God rather than it is due to human misbehavior [Table 3].

However, the majority of the FGD discussants did not believe that HIV/AIDS in a curse sent from God; rather they agreed it is due to human misbehavior.

One of the discussant, (24 year's old, male, Orthodox) expressed his view as follows:

".....For me, I agreed with that idea HIV/AIDS is not a curse sent from God, rather it is the result of engaging ourselves in risky sexual behavior....... Youth Friendly Service Utilization

Out of the total participants, only 228 (69.1\%) were using YFS and the major sources of information about YFS were media 117 (35.5\%) followed by health institution, $98(29.7 \%)$. Out of the total participants, 163 (71.5\%), 192 (84.2\%) and 86 $(37.7 \%)$ of them have got VCT, used SRH services and had ever visited the library and recreational services respectively. The participants were asked about their provider preferences and majority of them 272 (82.9\%) prefer the same sex YFS providers. Moreover, the participants of the FGD also support this finding.

One of the discussant, (18 year's old, male, Orthodox) expressed his view as follows: 
"..... The preference for the same sex had a chance to freely discuss our problem and for physical examination, especially that involve taking off my clothes. And the provider should be one that can understand the past and see the future. For instance,

I do not even be happy to be injected a medication by a female professional...."

The results of the study revealed that 191 (57.9\%) of respondents ever had sexual contact. Of these, 162 (84.8) were using condom and 157 (82.2\%) had sexual intercourse with their regular partner. The mean age at first sex debut was computed as 18.64 $( \pm 1.5)$ years and $50.3 \%$ of them started sex above or at the age of 18 years. However the FGD discussant said that age, fell in love, peer pressure, spending more time with opposite sexes, the presence of the night clubs were the reasons forwarded for the higher sexual activity among youths

One participant (22 year's old, female) expresses her view as follows:

"...... it is difficult to say or absolutely impossible to say the youths are not sexually active nowadays because they are currently easily exposed to peer pressure and high competition, especially among female youths to have boyfriend..........."Fifty seven (29.8\%) of the participants had more than one sexual partner during the study period.

This is also supported by the in-depth interview One participant (28 year's old, female) expresses her view as follows:

".... Currently it is difficult for these youth to be faithful with their regular partner rather they prefer to have sex with many partners and this could lead them to suffer from many problems,"

Two hundred four (61.8\%) of the participants were freely discussing about their personal issues, including reproductive health with a health care provider. Moreover, the FGD discussants clearly emphasize on the importance of confidentiality and privacy their information from a health care provider One of the discussant, (22 year's old, female, Orthodox) expresses her view as follows:

"........ I prefer to go for the YFS repeatedly and recommend to my friend if the health care provider able to keep our secret and examine us with good privacy............"

The main reason mentioned for not using YFS by the participants was they did not know where to go for such services $48(47.1 \%)$ [Table 4$]$. In addition to that, participants from the in-depth interview and FGD discussant support this finding.

One of the in-depth interview participants from semen health center, (28 years old, female, Nurse) expresses her view as follows:

"......the barriers to using YFS among youths in our institution were; feeling of shy, fear, anxiety and they prefer to have a separate area that helps them to get comprehensive service....."

In addition to the above one FGD discussant (18 year's old, female, Orthodox) expresses her view as follows:

".....youths might use the service if the service provider able to inform the youths about the service provided in detail and the consequence of late seeking treatment for their health problems......"

Predictor of Youth Friendly Service Utilization

Females were 3 times more likely to seek youth friendly service than males $[A O R=2.7,95 \% \mathrm{Cl}(1.2-$ 4.9)].Youths who had high knowledge were 7 times more likely to use youth friendly service than those who had low knowledge [AOR=7.08, 95\% Cl (1.4434.71)].Youths who had heard information about YFS from health institutions were 0.16 less likely to seek youth friendly service as compared with those who had heard from media[AOR $=0.16, \mathrm{Cl} 95 \%(0.04-$ 0.74)].Youths who had first sexual intercourse with commercial sex worker were 7 times more likely need youth friendly service than those who had first sexual intercourse with regular partner $[A O R=7.25$, 95\% Cl(1.42-37.15)][Table 5].

\section{DISCUSSION}

In this study, the major sources of information about YFS were media 117 (35.5\%). However, this finding is higher than a study done in Harar which showed media as source of information for only $22.8 \%$ participants [10]. Moreover, this finding also quite different from a study done in Georgia that indicates, youths seek most common source of information was close friends and peers [11]. This might be due to continuous advertisement of the youth friendly services (F/P, VCT, STI, SRH, recreation) through mass media (TV and FM radio). In this study, $50.3 \%$ of the study subjects had sexual experience at the age of 18 years and above. According to similar studies conducted in Moldova (26.9\%) and Tanzania (55\%) youth had sexual experiences before the age of 18 years and 19 years respectively $[12,13]$. This is probably due to early 
marriage was common in this area and this might be engaged youth in sexual activity at an early age.

One hundred sixty three $(71.5 \%)$ youth had VCT prior to the study. This figure is considerably higher than when it is compared with other studies in Jigjiga (60\%) [14].This might be because older youth may have had more sexual experiences and a higher risk exposure than younger ones and the difference of the study area.

Among non-users of youth- friendly services, $47.1 \%$ of them did not know where to go for seek YFS. The finding of this study is consistent with previous study reported in Zimbabwe (44\%) didn't know where to go [15]. However, this finding was higher as

Table 4: Practice of Respondents on YFS utilization in Mekelle town, 2013

\begin{tabular}{|c|c|c|}
\hline Characteristics & Frequency & Percent \\
\hline \multicolumn{3}{|l|}{ Ever used YFS $(n=330)$} \\
\hline Yes & 228 & 69.1 \\
\hline No & 102 & 30.9 \\
\hline \multicolumn{3}{|l|}{ Source of information } \\
\hline Media & 117 & 35.5 \\
\hline School teachers & 80 & 24.2 \\
\hline Health institutions & 98 & 29.7 \\
\hline Friends & 35 & 10.6 \\
\hline \multicolumn{3}{|c|}{ Preference of sex of the YFS provider } \\
\hline Same sex & 271 & 82.9 \\
\hline Opposite sex & 59 & 17.1 \\
\hline \multicolumn{3}{|c|}{ Ever undergone voluntary HIV testing $(n=228)$} \\
\hline Yes & 163 & 71.5 \\
\hline No & 65 & 28.5 \\
\hline \multicolumn{3}{|c|}{ Ever visited for library and recreational services $(n=228)$} \\
\hline Yes & 86 & 37.7 \\
\hline No & 142 & 62.3 \\
\hline \multicolumn{3}{|l|}{ Ever used SRH services $(n=228)$} \\
\hline Yes & 192 & 84.2 \\
\hline No & 36 & 15.8 \\
\hline \multicolumn{3}{|c|}{ Freely discuss about your personal issues $(R H)$ with a health care provider $(n=330)$} \\
\hline Yes & 204 & 61.8 \\
\hline No & 126 & 38.2 \\
\hline \multicolumn{3}{|c|}{ Do you have a sexual experience $(n=330)$} \\
\hline Yes & 191 & 57.9 \\
\hline No & 139 & 42.1 \\
\hline \multicolumn{3}{|l|}{ Were you using condoms $(n=191)$} \\
\hline Yes & 162 & 84.8 \\
\hline No & 29 & 15.2 \\
\hline \multicolumn{3}{|c|}{ With whom did you have the first sexual intercourse $(n=191)$} \\
\hline Regular partner & 157 & 82.2 \\
\hline Commercial sex worker & 13 & 6.8 \\
\hline Husband/wife & 21 & 11.0 \\
\hline \multicolumn{3}{|c|}{ Have more than one sexual partner currently $(n=191)$} \\
\hline Yes & 57 & 29.8 \\
\hline No & 134 & 70.2 \\
\hline \multicolumn{3}{|l|}{ Sex start age category $(n=191)$} \\
\hline 18 and above & 96 & 50.3 \\
\hline Below 18 & 95 & 49.7 \\
\hline \multicolumn{3}{|l|}{ Reason for not using YFS } \\
\hline Did not know where to go & 48 & 47.5 \\
\hline Health facility too far from this & 19 & 18.4 \\
\hline Too shy & 24 & 23.5 \\
\hline Peer pressure & 11 & 10.6 \\
\hline
\end{tabular}


compared with a study done in Jimma that showed location was widely known and only $2 \%$ did not know where to find youth-friendly health services for reproductive health [16]. This might be due to the fact that more than half of the youth had a negative attitude of towards YFS, so the negative attitude leads them for not using YFS.

In this study, 162 (84.8\%) used condom in their first sexual experience. However, this finding was higher as compared with a report from EDHS 2011 [6]. This might be due to the fact that majority youth had knowledge about YFS including STI and HIV/AIDS and this study conducted in a city in which in case of EDHS it includes both urban and rural. Ethiopian DHS 2011 also indicated that knowledge of family planning is high as $98 \%$ among currently married women and $97 \%$ among currently married men and a study done in Jimma which was $95 \%[6,16]$, which is consistent with the finding of this study (94.5\%).

The study revealed that $57.9 \%$ of respondents ever had sexual contact. However, this finding was higher as compared with a study done in Harar, which was $37.9 \%$ [17]. This might be due to the time gap between these two studies. In this study $82 \%$ of the youth had regular sexual partner and $94 \%$ had heard about VCT service this was consistent with the finding from Harar which was $77.7 \%$ and $100 \%$ respectively [17].

Knowledge of YFS is a prerequisite to obtain access to suitable service, timely and effectively and in this study, $71.5 \%$ the youth was used VCT and this was consistent with the review done in 5 African countries that showed knowledge of reproductive health issues and services was reported as a pull factor for use of the service which was supported by $80 \%$ of the study [18]. However, finding of this study was higher as compared with the result of Nigeria in which $63.2 \%$ of the students were aware of VCT (59.1\%) and $26.4 \%$ mass media had taken an HIV test at one time or the other before the study. This might be due to the fact that in Nigeria the study showed that most of the students believe that they were certain they were not infected that why they were not willing to go for VCT and most of the students did not know where VCT services could be obtained and knowledge of what VCT entails was also low. The finding of this study also revealed that $57.9 \%$ of respondents ever had sexual contact. However the finding was higher as compared with a study done in Nigeria, which was $29.9 \%$. This might be due to differences in the culture and study area.
Out of the review in 5 studies in Africa, four of them $(80 \%)$ indicated that most adolescent said as they would feel comfortable to discuss their problems when there is confidentiality and privacy. The youths indicated that separate service points or clinics were better for them because they have fear of embarrassment from being known by adults that they are sexually active when they use the same service. And this in-turn creates confidence in the youth to freely discuss about any problem with their family [18]. Moreover, findings of this study supports those in which $200(61.8 \%)$ of the participants freely discussed about their personal issues including reproductive health with their family members. This was also supported by the FGD participants.

Sixty percent of the studies conducted in Africa reported that convenient location which was far away was preferred by some adolescents. However, others preferred the location of services to be near their home and the cited reasons for satisfaction as short waiting time, being attended to on time and on a first come first served basis [18]. Similarly the findings of this study revealed that $18 \%$ of the youth cited that health facility too far from their home for not utilizing of YFS.

Youths were also interested to be involved or served by their peers. The review done in 5 African countries found youth's involvement as a pull factor in $60 \%$ of the studies [18]. However, our finding differed from those in which $10.6 \%$ of the youth cited peer pressure for not utilizing of YFS in their catchment area.

Female were more likely to utilize the youth friendly service than males. This could be due to the fact that females have higher morbidity as compared with males.

Knowledge about YFS is a requirement to obtain the service early. According to the present study, Youths who had higher knowledge were more likely get YFS than their counterparts.

Youths who had first sexual intercourse with commercial sex worker were more likely in obtaining youth friendly service than those who had first sexual intercourse with a regular partner. This could be, these youth may assume that commercial sex workers had a high chance for transmission of disease including HIV/AIDS

The study suffers from the Usual limitations of a cross sectional study. The knowledge and attitude towards YFS among parents were not addressed through this study. The study also did not discover any information from the manager side of YFS. However, the study team had made an effort to dig 
out possible information and to make the interview as private as possible to minimize such biases.

\section{CONCLUSION}

The majority of youths have got YFS and source of information was media. Among non-users majority participants did not know where they get youth friendly service. Even if a huge number of youths had higher knowledge about youth, but a significant amount of the participants had negative attitude towards utilization of YFS. Much number of participants had misconceptions about HIV/AIDS. Source of information about YFS, knowledge and with whom you start sex were an important predictor of YFS utilization.

\section{RECOMMENDATION}

The government and stakeholders working in this area should give attention to expanding youthfriendly services and work with health facilities to raise awareness and encourage for having positive attitudes towards using YFS in the area. The youth should be informed about where YFS are offered and helped to make use of these services. Training should be provided to health service providers for further sensitize them to the special health needs of youth. Health promotion regarding YFS at the community level should be carried out by the local health administrative offices. Furthermore, it is important to build strong social support for the youth; from youth, from the general community, particularly families, religious leaders, school teachers, health providers and administrative bodies.

\section{ACRONYMS}

AYA; Africa Youth Association, AYFRH; Adolescents Youth Friendly Reproductive Health,

DHS; Demographic and Health survey, FGAE; Family Guidance Association of Ethiopia

FP; Family Planning, HIV/AIDS; Human Immune Virus/Acquired Immune Deficiency

ICPD; International Conference on Population and Development, RH; Reproductive Health, SRH; Sexual Reproductive Health; TRHB; Tigray Regional Health Bureau

YFS; Youth Friendly Service

\section{Competing interests}

The authors declare that they have no competing interests

\section{Authors' contribution}

KK, SB, MA participated in proposal development, data collection, analyzing of the data and developing of the manuscript. All authors read and approved the final manuscript.

\section{ACKNOWLEDGEMENT}

It gives us a great reputation and opportunity to thank the University of Mekelle for financial support and our earnest thanks to study participants who spent their valuable time responding to the questionnaire accordingly.

\section{REFERENCES}

1.Bukusi E. 149 Contraception for adolescents and young people in the era of HIV/AIDS. International Journal of Gynecology \& Obstetrics ; 2009 Oct;107:S13. Available from: http://dx.doi.org/10.1016/s0020-7292(09)60049-7

2.Yerdaw M, Nedi T, Enquoselassie F. Assessment of Awareness of HIV/AIDS among Selected Target Groups in and around Addis Ababa, Ethiopia. African Journal of Reproductive Health;6(2):30. Available from: http://dx.doi.org/10.2307/3583128

3.World Health Organization (WHO). SpringerReference ; Available from: http://dx.doi.org/10.1007/springerreference 70205

4. Human security and sexuality in the IPPF Africa Region. Chinese Business Review; 2010 Mar 28;09(03). Available from: http://dx.doi.org/10.17265/1537-1506/2010.03.003

5.Fekadu Z. Casual sex-debuts among female adolescents in Addis Ababa, Ethiopia. Ethiopian Journal of Health Development; 2001 Feb 1;15(2). Available from: http://dx.doi.org/10.4314/ejhd.v15i2.9884

6. Erulkar AS, Mekbib T-A, Simie N, Gulema T. Differential use of adolescent reproductive health programs in Addis Ababa, Ethiopia. Journal of Adolescent Health; 2006 Mar;38(3):253-60. Available from: http://dx.doi.org/10.1016/i.jadohealth.2005.03.026

7.Health: HIV and AIDS: Sub-Saharan Africa. Encyclopedia of Women \& Islamic Cultures; Available from:

http://dx.doi.org/10.1163/18725309 ewic ewiccom 0172g 
8.Girma Y. Infant Feeding Practice and Associated Factors among HIV Positive Mothers Enrolled in Governmental Health Facilities in Mekelle Town, Tigray Region, North Ethiopia. Journal of HIV/AIDS and Infectious Diseases; Available from: http://dx.doi.org/10.17303/jaid.2014.401

9.Motuma A, Syre T, Egata G, Kenay A. Utilization of youth friendly services and associated factors among youth in Harar town, east Ethiopia: a mixed method study. BMC Health Serv Res;16(1). Available from: http://dx.doi.org/10.1186/s12913-016-1513-4

10. Skarbinski J. The Burden of Out-of-Pocket Payments for Health Care in Tbilisi, Republic of Georgia. JAMA ; 2002 Feb 27;287(8):1043. Available from: http://dx.doi.org/10.1001/jama.287.8.1043

11.Leep CJ. 2005 National Profile of Local Health Departments. Journal of Public Health Management and Practice; 2006 Sep;12(5):496-8. Available from: http://dx.doi.org/10.1097/00124784-200609000$\underline{00019}$

12.Wubie AJ, Girma M, Bihonegn A, Alemu A, Lemma $M$. Verification of splitting queen - rearing technique at the backyards of beekeeping farmers in Wag-himra zone, Amhara Region, Ethiopia. IOSR Journal of Agriculture and Veterinary Science;7(6):32-8. Available from: http://dx.doi.org/10.9790/2380-07613238

13.Fergusson DM, John Horwood L, Ridder EM. Abortion in young women and subsequent mental health. Journal of Child Psychology and Psychiatry ;47(1):16-24. Available from: http://dx.doi.org/10.1111/j.1469-7610.2005.01538.x

14. Woldie M, Jirra C, Tegegn A. An assessment of the free health care provision system in Jimma town, Southwest Ethiopia. Ethiopian Journal of Health Development; 2006 Apr 21;19(3). Available from: http://dx.doi.org/10.4314/ejhd.v19i3.9997

15.Ikechebelu I, Udigwe G, Ikechebelu N, Imoh L. The knowledge, attitude and practice of voluntary counselling and testing (VCT) for HIV/AIDS among undergraduates in a polytechnic in south-east Nigeria. Nigerian Journal of Medicine; 2007 Jan 11;15(3). Available from: http://dx.doi.org/10.4314/njm.v15i3.37222
16.Kim J. School Socioeconomic Composition and Adolescent Sexual Initiation in Malawi. Studies in Family Planning; 2015 Sep;46(3):263-79. Available from: $\quad$ http://dx.doi.org/10.1111/j.17284465.2015.00029.x

17. Dirar A. Factors Contributing to Voluntary Counseling and Testing Uptake among Youth in Colleges of Harar, Ethiopia. SJPH; 2013;1(2):91. Available from: http://dx.doi.org/10.11648/j.sjph.20130102.17

18. Annabel. s Erulker, Charles J. What is youthfriendly? Adolescent's preferences for RHS in Kenya and Zimbabwe. African journal of RH, 2005 Vol 9 no $3(1-8)$ 